\title{
Health visitors' perception of their role in the universal childhood immunisation programme and their communication strategies with parents
}

\author{
Sarah A. RedselI ${ }^{1}$, Helen Bedford ${ }^{2}$, A. Niroshan Siriwardena ${ }^{3}$, Jacqueline Collier ${ }^{4}$ and Philippa Atkinson $^{5}$ \\ ${ }^{1}$ Principal Research Fellow, School of Nursing, Midwifery and Physiotherapy, University of Nottingham, Nottingham, UK \\ ${ }^{2}$ Senior Lecturer in Children's Health, UCL Institute of Health, London, UK \\ ${ }^{3}$ Professor of Primary Care, Lincoln School of Health and Social Care, University of Lincoln, Lincolnshire, UK \\ ${ }^{4}$ Professor of Health Services Research, School of Nursing, Midwifery and Physiotherapy, University of Nottingham, \\ Nottingham, UK \\ ${ }^{5}$ Health Visitor, St Ann's Health Centre, Nottingham City Primary Care Trust, Nottingham, UK
}

\begin{abstract}
Aim: This study explored health visitors' perception of their role in the universal childhood immunisation programme with particular emphasis on influencing factors and communication strategies. Background: The majority of parents' consent to immunisation, but some find decision-making in this area difficult and have unmet information needs. In the United Kingdom, health visitors routinely provide immunisation information for parents, whereas general practitioners (GPs) and practice nurses tend to administer vaccines and respond to parents/carers' questions. Research has investigated health professionals' views and knowledge about immunisation, but less is understood about health visitors' role and how they communicate with parents. Method: Following the Local Research Ethics and Research Governance permissions, all health visitors $(n=120)$ working in one county in the United Kingdom were invited to participate in the study. Semistructured interviews $(n=22)$ were undertaken using a prompt guide. The interviews were transcribed verbatim. Thematic analysis using an iterative approach was used to explore the data facilitated by NVIVO ${ }^{\mathrm{TM}}$ software. Findings: Five themes emerged from the interviews. These were health visitors' professional role; identity and perceived barriers and communication strategies, parents' right to choose, confidence in measles, mumps, and rubella (MMR) vaccination and communicating with migrant families about immunisation. There were differences between the health visitors in their perceptions of their roles, skills and knowledge and communication strategies. Health visitors perceived that GPs and practice nurses took a paternalistic approach to the provision of immunisation information, while they used a parental decisionmaking model. Health visitors reported a loss of professional confidence following the MMR crisis. Conclusion: Given the evidence that some parents find it difficult to gain the information they need about immunisation and health visitors' acknowledgement that their usual communication models were not effective during the MMR crisis, we feel specific communication skills training is needed to enable health professionals to provide parents with appropriate decision support.
\end{abstract}

Key words: communication; health visitors; immunisation; MMR; decision-making

Received 13 October 2008; accepted 20 October 2009; first published online 3 December 2009

Correspondence to: Dr Sarah A Redsell, Principal Research Fellow, School of Nursing, Midwifery and Physiotherapy, University of Nottingham, A Floor, South Block, Nottingham, NG7 2UH, UK. Email: sarah.redsell@nottingham.ac.uk

(C) Cambridge University Press 2009 


\section{Introduction}

In the United Kingdom, childhood immunisation is voluntary and in England uptake of primary immunisations by 2 years of age against diphtheria, tetanus, polio, pertussis, Haemophilus influenzae type $\mathrm{B}$, and meningitis $\mathrm{C}$ has been 93-94\% for the past 5 years (NHS Information Centre, 2007-08). This almost reaches the 95\% target level to ensure herd immunity against infectious diseases. Concerns about the safety of measles, mumps, and rubella (MMR) vaccine were raised in 1998, following the publication of a paper that was widely interpreted as suggesting a link with autism and bowel disease (Wakefield et al., 1998). However, the findings have not been subsequently supported (Bedford et al., 2005), and the paper has been discredited. In England, following a fall in the uptake of MMR vaccine to a low of $79 \%$ in 2003 , uptake rose to $85 \%$ in 2006-07 and remains at 85\% (NHS Information Centre, 2007-08). There has also been an increase in the proportion of parents who consider MMR to be completely safe or to carry only a slight risk (Smith et al., 2007). However, the MMR immunisation rate is still lower than the peak coverage of 92\% achieved in 1995-96 (Department of Health, 2004-05), and there has been a significant increase in cases of measles. In England, uptake of pre-school immunisation is also low with $78 \%$ of children receiving their primary booster and $74 \%$ receiving the second dose of MMR by 5 years of age (NHS Information Centre, 2007-08).

Children who have not had the full course of immunisations include those who have commenced, but not completed, the course (undervaccinated children) and those who have had no vaccines at all (unvaccinated children). Undervaccinated children are more likely to be from minority or ethnic groups and/or have younger and/or less well-educated mothers who live near the poverty level, whereas unvaccinated children tend to be white, with highly educated, well-paid married mothers who have concerns about the safety of immunisations (Samad et al., 2006), and articulate that doctors have little influence over their decisions (Smith et al., 2004). Parents of unvaccinated children report more concerns about the risk of vaccine side effects (Sporton and Francis, 2001) than about dangers of the disease, whereas parents of vaccinated children are more concerned about the risk of disease (Evans et al., 2001). However, the situation is clearly far more complex than this, as parents of vaccinated children also express concerns about vaccine safety (Evans et al., 2001; Raithatha et al., 2003, Salmon et al., 2005).

Some parents find it difficult to decide whether or not to immunise their child (Evans et al., 2001), and studies have explored whether they have unmet information needs. In a UK survey, completed by 76/110 parents who defaulted for one or more primary immunisations (Smailbegovic et al., 2003), responders reported that although they commonly asked health professionals for advice, over a quarter of respondents perceived the information provided to be poor. Parents of unvaccinated children reported that health professionals provided unbalanced information and this was seen as an obstacle to their decisionmaking. This criticism of lack of, or poor quality of, information provided has been consistently reported (Evans et al., 2001; Sporton and Francis, 2001; Yarwood et al., 2005). In the United Kingdom, decision-making has become more difficult for some parents as a result of the public controversy over the safety of the MMR vaccine. Concerns about the safety of the MMR vaccine were reported by both MMR-accepting and MMR-refusing parents in a survey $(n=996)$ conducted in North East England (Casiday et al., 2006). Qualitative studies (Evans et al., 2001; Raithatha et al., 2003; McMurray et al., 2004) conducted subsequently revealed that some parents were not convinced by the Department of Health's reassurances that the vaccine was safe and accepted it unwillingly. The advice provided by general practitioners (GPs) and health visitors is generally seen as trustworthy, but their influence is limited by concerns over perceptions of financial and political partiality (McMurray et al., 2004).

Health professionals' views and knowledge about immunisation have been found to be suboptimal (Harris et al., 2001; Petrovic et al., 2001; Cotter et al., 2003; Henderson et al., 2004). They have been reported as not feeling completely confident about explaining specific vaccine issues (Petrovic et al., 2001; Henderson et al., 2004) to disagree with or to have reservations about some vaccine policies (Petrovic et al., 2001; Henderson et al., 2004), and not to use or not to be aware of 
nationally available resources on immunisation (Petrovic et al., 2001; Cotter et al., 2003). One study found that a proportion believed that single MMR vaccines should be available on the National Health Service (NHS; Macdonald et al., 2004). Furthermore, health professionals have expressed reservations about giving their own child(ren) specific vaccines (Petrovic et al., 2001; Brownlie and Howson, 2006). Clearly, some health professionals' understanding of the evidence is far from robust, which may lead them to providing inaccurate information to parents.

Concerns about the inconsistencies in health professionals' knowledge, views, and practice in relation to immunisation have not gone unnoticed. In 2004, the National Service Framework for Children, Young People and Maternity Services identified a need to improve all aspects of practice in relation to immunisation (Department of Health, 2004). A survey of UK Primary Care Trusts, published in 2004, found that immunisation training for health professionals was variable and over half of trusts surveyed were concerned about their capacity to provide an effective immunisation programme mainly due to a lack of specialist input, time, and funding (Cummins et al., 2004). National minimum standards for immunisation training have been introduced (Health Protection Agency, 2005). Most of these are concerned with improving practitioners' knowledge, although one core curriculum session focuses on communication. However, little is known about communication within immunisation consultations. Therefore, it must be difficult for primary care trusts (PCTs) to ensure that the content of the communication aspect of the training is appropriate.

Studies reporting health professionals' communication with parents about immunisation are rare. Only one US study was identified which specifically explored risk/benefit communication (Davis et al., 2001). In the United Kingdom, health visitors provide information to parents about immunisation; GPs and practice nurses administer the vaccine, but tend not to provide information unless it is requested by parents or carers (Department of Health, 2008). Research has been undertaken looking at health professionals' views and knowledge about immunisation (Cotter et al., 2003; Henderson et al., 2004), but less is understood about how health visitors, in particular, communicate with parents.

\section{Aims and objectives}

This study aimed to explore health visitors' perception of their role in the universal childhood immunisation programme with particular emphasis on influencing factors and communication strategies. The specific objectives were

- to describe the self-reported role of health visitors in relation to immunisation;

- to explore underlying factors influencing health visitors' approaches to the advice they give parents;

- to describe health visitors' perceptions of the communication process with parents of children approaching primary immunisation and MMR.

\section{Method}

\section{Sampling and recruitment}

Health visitor managers working in a UK county and a UK city PCT were contacted and informed about the study. Information packs $(n=120)$ were distributed to health visitors during eight locality meetings within the two trusts (SR). The information packs asked interested health visitors to return a reply slip detailing their name and telephone contact details together with information about their working environment. This information was intended to be used as a guide to ensure a purposive sample of health visitors working in different locations and in different ways and was included in the study. Local Research Ethics and Research Governance approvals were obtained.

\section{Data collection}

Data collected from health visitors reply slips included details of their working environment (rural, affluent, deprived, high/low minority ethnic populations/Children's Centres, or GP attached). It was intended to draw a purposive sample from the health visitors who returned their reply slip using this data. However, in practice, all those who returned their reply slip within the data collection phase were invited to be interviewed. All interviews were conducted by the same interviewer (SR), face to face at a health centre local to each health visitor. The semistructured interviews used a topic guide based on findings from a literature review and discussions 
within the research team. Topics for inclusion covered issues such as health visitors' responsibilities within the immunisation programme, the process of discussing immunisations, communicating with families who were unsure about or refused immunisation, immunisation training and the MMR vaccine. The guide was used flexibly during the interviews to allow health visitors to describe their experiences, and it was revised and refined throughout the data collection phase to reflect themes emerging from the data analysis. The length of time for the interviews varied among participants, but all lasted less than an hour.

\section{Data analysis}

Interviews were audio recorded and transcribed verbatim. Data analysis was undertaken in parallel with the interviews, enabling the topic guide to be modified in light of the emerging themes. A preliminary analysis was conducted by SR on five transcripts that were examined independently by $\mathrm{HB}, \mathrm{NS}, \mathrm{JC}$, and PA, and the key themes agreed (Grbich, 1999). Thematic analysis continued on the accumulating data. The themes were then coded and categorized, using NVIVO $7^{\mathrm{TM}}$ (2007) software; checked against the original data set and adjusted where necessary. SR and PA agreed the final coding frame and the reassignment of the data to the themes.

\section{Results}

Twenty-four health visitors responded to the study invitation. Of these, twenty-two were interviewed. The remaining two were not available for interview during the data collection phase. Health visitors described their working environments in a number of ways including rural $(n=4)$, inner city $(n=10)$, and city suburbs $(n=6)$; affluent $(n=6)$ and deprived $(n=11)$; mixed $(n=5)$; and high rates of minority ethnic groups $(n=8)$. Townsend scores for the localities where the health visitors worked ranged from -3.7 to +10.17 (positive scores equal greater levels of deprivation; Townsend et al., 1988). Ways of working were described as GP attached $(n=10)$, geographical $(n=7)$, and linked to Children's centres $(n=4)$ or the homeless team $(n=1)$. Health visitors followed the national

Primary Health Care Research \& Development 2010; 11: 51-60 immunisation policy as outlined in the 'Green Book' (Department of Health, 2008).

Five main themes emerged from the interviews. These were health visitors' professional role in relation to the universal childhood immunisation programme; identity and perceived barriers and communication strategies; parents' right to choose; confidence in MMR vaccination; and communicating with migrant families about immunisation.

\section{Health visitors' professional role; identity, and barriers}

Health visitors talked about their role in relation to the child health promotion programme. This involved educating parents by raising awareness about public health issues that included immunisation. All health visitors said that they were required to discuss immunisations with parents during the birth visit that usually occurred when an infant was 14-28 days old. However, most suggested that this was not the most appropriate time to go into great detail about immunisations, as parents usually had other priorities. Most described how during the Birth visit they would assess the mother's receptiveness to information beyond her immediate needs. Some, but not all, described how they would follow up these initial discussions with another home visit before the first primary immunisation at 8 weeks.

In the ideal world perhaps a vaccine would be a separate visit, because we give them such a lot of information on that first visit. They probably feel-sometimes I feel overloaded, so I'm sure sometimes they do. (HV113)

Health visitors described the 6-8-week checkup for the infant and how, when this was undertaken, parental consent for the vaccine was usually obtained by a GP, whereas the immunisations were administered (usually) by a practice nurse. Concerns were expressed about this split system with some health visitors reporting that they felt the GP and practice nurse adopted a less parentcentred approach to information provision than themselves. In contrast their self-perception was one of not being tainted by financial incentives, but as enablers of parental choice.

They have a different incentive, which is financial at the end of the day. I'm sure ultimately it's about the client's health but in 
terms of them reaching their - they're under pressure to reach their targets. (HV105)

There was uncertainty about the process of parental consent. There were mixed views on infor$\mathrm{mal} / \mathrm{implicit}$ consent, that is, the fact that a parent had brought their infant to the immunisation appointment at the practice being seen as consent. Some health visitors thought that it was acceptable for the immunisation programme to operate in this way, whereas others thought written consent was vital.

Views about whether or not health visitors should administer immunisations were mixed. Some health visitors stated that immunising children was integral to health visiting practice and reported that they were trained immunisers. Within this group, a few said they routinely immunised children and the rest undertook targeted immunisations. Other health visitors thought that they should not be immunising at all. The reasons for not immunising were complex and included the view that health visitors' main responsibility was the provision of information, whereas the administration of immunisation was the practice nurses' job. Others talked about their lack of competence because they were not immunising on a regular basis.

If I'm not doing it on a regular basis which I'm not because basically I would refuse to do it because I don't see it as part of my role and therefore I'm unsafe. (HV120)

The majority of health visitors reported that they had very little input into the process of offering and delivering pre-school boosters, and this was seen as predominantly an administrative task for the practice. Apart from those health visitors, who were the immunisers for their caseloads, most did not see it as their role to actively promote preschool boosters.

\section{Health visitors' professional role - communication strategies}

Health visitors presented themselves as experts in communicating with parents about immunisations. They referred to 'knowing the right time to talk to parents about immunisation' that involved being sensitive to their needs and priorities. Most referred to having a standard chat, which involved providing information about the immunisation schedule for new parents and changes to the schedule for parents with older children. The process of these discussions included aspects such as checking parental knowledge and previous experiences, providing explanation about the vaccinations, addressing fears and providing reassurance particularly for new parents and in relation to MMR, and responding to parents' questions.

The health visitors also talked about actively promoting the immunisation programme. This involved approaching parents with an expectation that they would have their child immunised. Health visitors reported that most parents expected this approach. They referred to specific strategies they used to encourage uptake. These included repeating and reinforcing the information by revisiting the subject of immunisations during every meeting as well as exploring and challenging parents about myths. Health visitors also talked about how they might persuade parents who were unsure. Different strategies were identified as being useful depending upon the parent. The most frequently cited strategies were discussing herd immunity and raising awareness about the potential threats of disease in particular focusing on outbreaks and scares.

You have to say, look you know there is an infinitesimal risk with immunisations because we don't know how your child is going to react and you know that's an awful thing you know to come to terms with but we do know that is you don't protect your child they are very, very much at risk of developing that disease. (HV101)

Health visitors also reported that they tried to persuade parents through sharing and encouraging social norms that included divulging information about their own immunisation behaviours and encouraging parents to talk to peers. They described the difficulties of persuading and actively pursuing parents in terms of a trade off between pressurizing and maintaining a relationship with them.

You don't want to ruin a relationship because if they're not letting you in you can't do any work at all ... You know the balance has been right about you know having responsibility to talk about public health issues but not alienating her so that you can't get in to do any work at all. (HV120)

Primary Health Care Research \& Development 2010; 11: 51-60 
Some health visitors reported that they had not had any specific training on communication with parents about immunisations. Most said that they were experienced health visitors and, as such, felt they had no current need to improve their communication skills; but they thought that it would be useful for students undergoing health visitor training. A few suggested that communication skills training might help them with their role.

\section{Parents' right to choose}

Health visitors said that some parents responded to them as a trusted health professional, but others perceived them to be a government agent who could not be trusted to provide unbiased information. Parents' information needs could be high, particularly in affluent areas. However, in some of the more deprived areas, health visitors thought that parents' information needs were extremely low and reported that they did not question the system at all. These parents often had other priorities and were simply not interested in knowing what infections the immunisations protected their child against. They felt that some families just wanted to be told what to do. Health visitors reported modifying their practice to accommodate this by providing them with just the basics of timing and administration of immunisations.

The majority of health visitors talked about treating parents as the decision-makers with the right to choose whether or not to have their child immunised. However, if parents made the choice not to have their child immunised, this was not necessarily seen as the right choice. Most reported that they would leave the door open for parents to change their mind, but reiterated that they would check 'parents' final decision'. Parental refusal was documented.

Ultimately it's their choice we can't force them to have it but you just give them the sort of you know the information they need to make an informed choice and then you know if they decide not to come or they decide not to have it then we write it in the notes. (HV108)

Non-attendance for immunisation appointments and parental choice was also raised in relation to home immunisation with different views emerging.

Primary Health Care Research \& Development 2010; 11: 51-60
Although some health visitors supported the view that they were helping families to access services by immunising at home, others felt that if families did not attend repeated immunisation appointments, this indicated that they did not want their child to have them, a view which should be respected. Some health visitors felt that parents failed to attend immunisation appointments because of other priorities. In this case, immunising at home took the responsibility of attendance away from them, thereby giving them permission to miss appointments.

\section{Confidence in MMR vaccination}

Health visitors described their caseloads in terms of middle class and low-income families. They reported that the middle class families needed more information about MMR in order to provide informed consent. Most health visitors referred to the original Lancet research as discredited and reported that parental confidence in MMR was improving. They reported that a few parents continued to seek single vaccines for MMR, but many parents who had opted for single vaccines for previous children were now consenting to triple vaccines for subsequent children.

I rarely get anybody who says but I've heard of something, which is not good for you whereas I used to get that because of the MMR being top of the headlines. I don't really get that in the last sort of eighteen months I haven't had much of oh well we've heard the bad news. (HV104)

Although MMR was viewed as a recovering situation, health visitors thought that some public mistrust continued. They described how some parents, who were still unsure, delayed immunisation.

Certainly the MMR vaccine gets delayed. Sometimes 'cos parents are either not sure about it or they've had conflicting information and they still don't feel happy about giving the vaccine so they tend to put it off. (HV122)

Most health visitors admitted that they had been swept along with the tidal wave of concern about MMR and said that they thought it had affected their practice at the time. Some reported that they found it difficult to talk to parents with 
confidence about MMR and said they had done their own research to convince themselves it was safe. Many felt that they had not been provided with sufficient timely information, from the Department of Health, to help them convince parents that the immunisation was safe. However, they all reported that they now had greater confidence in MMR and were happy to discuss it with parents.

\section{Communicating with migrant families about immunisation}

Many health visitors reported having asylum seekers and economic migrants on their caseload. Most reported differences in the immunisation schedules between the United Kingdom and their home country. They described how some families arrived with incomplete health records and health visitors worked with the practice to ensure that children received all their immunisations. Some mentioned that these children may end up overvaccinated, but justified this as being better than being undervaccinated. Health visitors described the uptake of immunisation within these groups as good.

In terms of transfer-ins we have a responsibility with them in checking the immunisations that they've had. So again that means liaising with the public health department 'cos sometimes the family will come and say well we just followed the programme in Malaysia I don't know what the programme in Malaysia is. So it's again finding out well what have they had here what does that mean. (HV105)

Most health visitors reported that having families on their caseload who did not speak English was challenging for their practice. They described how it could be difficult to ensure that these families were fully informed about the options available to them. Those with large numbers of non-English speaking families on their caseload described routine use of the interpreting service to provide immunisation information to families. They also talked about using translated leaflets to enable families to understand the UK immunisation schedule. Some health visitors raised concerns about whether or not these leaflets were useful, as many of the families on their caseloads had low literacy skills.

\section{Discussion}

The Healthy Child Programme advises health professionals that 'every contact should be used to promote immunisation' (Department of Health, 2009). Health visitors were aware that this was required but expressed concerns about how difficult this was to put into practice, especially during a birth visit. They indicated that parents had a lot to think about during a birth visit and that some found it difficult to assimilate all the information being provided to them, which included advice about immunisations. There is evidence that parents consider the birth visit to be the best time to learn about immunisations, but they also want information on an on-going basis (Bedford and Lansley, 2006). Parents may not be able to think of all the immunisation-related questions they need answering during a birth visit, so they need to be given other opportunities to ask questions and gain information, before the first primary immunisation at 8 weeks. However, the core universal programme for new born infants only requires the health visitor to visit low priority families once (at the birth visit; Department of Health, 2009). Whereas the health visitors in this study stated that they believed it to be good practice to initiate a followup visit to families in-between the birth visit and the first primary immunisation at 8 weeks, many reported being unable to do so. Therefore, low-priority families may have too few opportunities to discuss immunisations with health visitors.

Some health visitors perceived the attitude of the GPs and practice nurses to be based on financial incentives to immunise and implied that practice doctors and staff were more coercive with parents. However, some also thought that parents perceived them to be agents of the State, which has also been reported elsewhere (McMurray et al., 2004). An early paper explored the views of primary health professionals $(n=58)$ in respect of how they met organizational targets, while at the same time respecting consent (Alderson et al., 1997). The results revealed that some health professionals took a paternalistic approach, advocating immunisation, while others took more account of the need for informed choice. In our study, health visitors used language associated with a parental decisionmaking model of communication, but there was an 
underlying expectation of compliance, which fits with a paternalistic model. Immunisation presents particular difficulties, and in that the extent of patient choice, which is an increasingly essential component of health-care encounters (Department of Health, 2003), has to be balanced against protecting the public through achieving herd immunity. However, parents want health professionals to move away from the current way of providing immunisation information towards a decisionsupport model (Jackson et al., 2008).

Some health visitors in our study made assumptions that poorly educated parents required less information than middle class parents. This finding is of concern because it suggests that some health visitors (and health professionals) decide (implicitly or explicitly) how much information to provide to particular groups of parents before the consultation. Undoubtedly, some parents will have information needs that differ from these expectations, and if they are not met, this could lead to frustration with the consultation (for both parties). Parents may not feel confident in the health visitor's abilities and may seek advice from sources such as the Internet, which may be illinformed. If they are unable to obtain the information they need elsewhere, they may choose to withdraw from the immunisation programme.

There were different views about the extent to which health visitors thought they should be involved in the immunisation programme. Some believed that their role included the entire process from giving advice to administering immunisations, whereas others considered that they should only be providing information to parents and leaving the rest to the general practice staff. Health visitors were dedicated to providing advice to parents about primary immunisation, but they did not have the same commitment in relation to pre-school boosters. This could partially explain the lower uptake of pre-school boosters reported in the literature (NHS Information Centre, 2007-08). They also had varying views about whether or not they should target non-attenders at home, with some believing it to be wrong to present themselves at a client's home ready to immunise their child. In addition, some of the health visitors who did not immunise had knowledge gaps in relation to the consent process. They were unaware that there is currently no requirement for written consent and that consent is an on-going process (Department of Health, 2008). It appears that there are gaps in health visitors' skills and knowledge in relation to the immunisation programme, which might be explained by the extent of their interest in the area. Health visitors are making decisions about which aspects of their practice to prioritize and for some immunisations are less important. These perspectives perhaps reflect different models of health visiting described in the literature, for example, bio-medical versus social empowerment (Elkan et al., 2000).

Health visitors reported that matching the immunisation schedule of families from overseas with the UK programme was a heavy administrative burden and they expressed concerns that some children ended up being overvaccinated as a result. This has also been reported previously (Alderson et al., 1997). Health visitors thought that the culture of compliance with immunisations was stronger in migrant families. This may be supported by evidence as, in some BME groups, the elders in the community encourage immunisation because of past experience of the diseases (Condon, 2002). Although health visitors who regularly work with BME groups reported regular use of translators, those who worked with them infrequently did not. Linguistic barriers were identified as a predictor of culture-related communication problems in a recent review of the literature (Schouten and Meeuwesen, 2006). The health visitors were concerned about the usefulness of translated information sources. There is evidence that BME families have different information needs and cannot be treated the same (Condon, 2002).

The principal investigator was previously employed as a health visitor and some of the respondents were aware of this. It is possible that this may have had an impact on the responses given, for example, the respondents may have felt that their views were being 'tested' in some way. During the interviews, some health visitors referred to other colleagues who did not share their proimmunisation views. It is possible that those who responded to the study invitation were more interested and pro-immunisation than those who did not. Clearly, the views of 22 health visitors working in two trusts in one region cannot be generalized more widely. However, it is hoped that these findings will contribute to the evidence of the need for interventions to help health 
professionals facilitate parental decision-making about immunisation.

\section{Conclusions}

There were important differences between the health visitors in their perceptions of their roles, skills, and knowledge and communication strategies in relation to the universal childhood immunisation programme. Health visitors also perceived differences in their approach with parents compared to that of other health professionals. They perceived that GPs and practice nurses took a paternalistic approach to the provision of immunisation information, while they used a parental decision-making model. While most did not consider they needed to improve their communication skills in this area of practice, they did acknowledge a loss of professional confidence in the wake of the MMR crisis. Given the evidence that some parents find it difficult to gain the information they need about immunisation (Smailbegovic et al., 2003) and the changing culture of health care towards more patient choice (and shared decision-making), we feel that specific communication skills training is needed to enable all health professionals to provide parents with appropriate decision support. There is evidence that communication skills training can improve health professionals' self-efficacy and ability to perform communication tasks (Ammentorp et al., 2007). Better communication skills for all health professionals involved in providing immunisation information might reduce the impact of another vaccine scare.

\section{Acknowledgements}

The authors thank the health visitors and their managers for contributing to this research.

\section{Funding}

This research was funded by an internal grant from the School of Nursing, University of Nottingham.

\section{References}

Alderson, P., Mayall, B., Barker, S., Henderson, J. and Pratten, B. 1997: Childhood immunisation: meeting targets yet respecting consent. European Journal of Public Health 1997, 95-100.
Ammentorp, J., Sabroe, S., Kofoed, P.E. and Mainz, J. 2007: The effect of training in communication skills on medical doctors' and nurses' self-efficacy. A randomized controlled trial. Patient Education \& Counselling 66, 270-77.

Bedford, H. and Lansley, M. 2006: Information on childhood immunisation: parents' Views. Community Practitioner 79, 252-55.

Bedford, H., Sengupta, N., Elliman, D. and Booy, R. 2005: Measles: prevention. Clinical Evidence 13, 373-87.

Brownlie, J. and Howson, A. 2006: Between the demands of truth and government: Health practitioners, trust and immunisation work. Social Science and Medicine 62, 433-43.

Casiday, R., Cresswell, R., Wilson, D. and Panter-Brick, C. 2006: A survey of UK parental attitudes to the MMR vaccine and trust in medical authority. Vaccine 24, 177-84.

Condon, L. 2002: Maternal attitudes to preschool immunisation about ethnic minority groups. Health Education Journal 61, 180-89.

Cotter, S., Ryan, F., Hegarty, H., McCabe, T.J. and Kearne, E. 2003: Immunisation: the view of parents and health professionals in Ireland. Eurosurveillance 8, 145-50.

Cummins, A., Lane, L., Boccia, D. and Crowcroft, N.S. 2004: Survey of local immunisation training in England - the case for setting national standards. Communicable Disease \& Public Health 7, 267-71.

Davis, T.C., Fredrickson, D.D., Arnold, C.L., Cross, J.T., Humiston, S.G., Green, K.W. and Bocchini, J.A. Jr 2001: Childhood vaccine risk/benefit communication in private practice office settings: a national survey. Pediatrics 107, E17, Feb.

Department of Health. 2003: Building on the best choice, responsiveness and equity in the NHS. Crown copyright Retrieved 6 May 2008 from http://www.dh.gov.uk/en/ Publicationsandstatistics/Publications/PublicationsPolicyAnd Guidance/DH_4075292

Department of Health. 2004: National service framework for children, young people and maternity services. London: The Stationary Office.

Department of Health. 2004-2005: NHS Immunisation Statistics. London, UK: The Stationary Office.

Department of Health. 2008: Immunisation against infectious disease. Retrieved 2 May 2008 from http://www.dh.gov.uk/ en/Publichealth/Healthprotection/Immunisation/Greenbook/ DH_4097254

Department of Health. 2009: Healthy Child Programme. Retrieved 18 November 2009 from http://www.dh.gov.uk/ prod_consum_dh/groups/dh_digitalassets/documents/digital asset/dh_107626.pdf

Elkan, R., Blair, M. and Robinson, J.J. 2000: Evidence-based practice and health visiting: the need for theoretical underpinnings for evaluation. Journal of Advanced Nursing 31, 1316-23.

Evans, M., Stoddart, H., Condon, L., Freeman, E., Grizzel, M. and Mullen, R. 2001: Parents perspectives on the MMR study: a focus group study. British Journal of General Practice 51, 904-10.

Grbich, C. 1999: Qualitative Research in Health, First edition. London, UK: Sage Publications Ltd.

Primary Health Care Research \& Development 2010; 11: 51-60 
Harris, T., Gibbons, C.R. and Churchill, M. 2001: Primary care professionals' knowledge of contraindications. Community Practitioner 74, 66-67.

Health Protection Agency. 2005: National minimum standards for immunisation training. Retrieved 22 May 2008 from http://www.hpa.org.uk/infections/topics_az/vaccination/ National_Immun_Train_Stand1.pdf

Henderson, R., Oates, K., Macdonald, H. and Smith, W.C. 2004: General practitioners' concerns about childhood immunisation and suggestions for improving professional support and vaccine uptake. Communicable Disease \& Public Health 7, 260-66.

Jackson, C., Cheater, F.M. and Reid, I. 2008: A systematic review of decision support needs of parents making child health decisions. Health Expectations 11, 232-51.

Macdonald, H., Henderson, R. and Oates, K. 2004: Low uptake of immunisation: contributing factors. Community Practitioner 77, 95-100.

McMurray, R., Cheater, F.M., Weighall, A., Nelson, C., Schweiger, M. and Mukherjee, S. 2004: Managing controversy through consultation: a qualitative study of communication and trust around MMR vaccination decisions. British Journal of General Practice 54, 520-25.

NVIVO7 $^{\text {TM }}$ 2007, Retrived 6 May 2008 from http://www. qsrinternational.com/products_nvivo.aspx

Petrovic, M., Roberts, R. and Ramsay, M. 2001: Second dose of measles, mumps and rubella vaccine: questionnaire survey of health professionals. British Medical Journal 322, 82-85.

Raithatha, N., Holland, R., Gerrard, S. and Harvey, I. 2003: A qualitative investigation of vaccine risk perception amongst parents who immunise their children: a matter of public health concern. Journal of Public Health Medicine 25, 161-64.

Salmon, D.A., Moulton, L.H., Omer, S.B., DeHart, M.P., Stokley, S. and Halsey, N.A. 2005: Factors associated with refusal of childhood vaccines among parents of schoolaged children: a case-control study. Archives of Pediatric and Adolescent Medicine 159, 470-76.
Samad, L., Bedford, H., Tate, A.R., Dezateux, C., Peckham, C. and Butler, N., and the Millennium Cohort Study Child Health Group. 2006: Differences in risk factors for partial and no immunisation in the first year of life. British Medical Journal 332, 1312-43.

Schouten, B.C. and Meeuwesen, L. 2006: Cultural differences in medical communication: a review of the literature. Patient Education \& Counselling 64, 21-34, Dec.

Smailbegovic, M.S., Laing, G.J. and Bedford, H. 2003: Why do parents decide against immunisation? The effect of health beliefs and health professionals. Child: Care, Health and Development 29, 303-11.

Smith, A., Yarwood, J. and Salisbury, D.M. 2007: Tracking mothers' attitudes to MMR immunisation 1996-2006. Vaccine 25, 3996-4002.

Smith, P.J., Chu, S.Y. and Barker, L.E. 2004: Children who have received no vaccines: who are they and where do they live? Pediatrics 114, 187-95.

Sporton, R.K. and Francis, S.A. 2001: Choosing not to immunise: are parents making informed decisions? Family Practice 18, 181-88.

The Information Centre. 2007-2008: NHS immunisation statistics England. Retrived 9 October 2008 from http:// www.ic.nhs.uk/statistics-and-data-collections/health-andlifestyles/immunisation/nhs-immunisation-statistics-england2007-08-[ns]

Townsend, P., Phillimore, P. and Beattie, A. 1988: Health and deprivation: inequalities and the north. New York, London: Croom Helm.

Wakefield, A.J., Murch, S.H., Anthony, A., Linnell, J., Casson, D.M., Malik, M., Berelowitz, M., Dhillon, A.P., Thomson, M.A., Harvey, P., Valentine, A., Davies, S.E. and WalkerSmith, J.A. 1998: Ileal-lymphoid-nodular hyperplasia, nonspecific colitis and pervasive developmental disorders in children. Lancet 351, 637-41.

Yarwood, J., Noakes, K., Kennedy, D., Campbell, H. and Salisbury, D. 2005: Tracking mothers attitudes to childhood immunisation 1991-2001. Vaccine 23, 5670-687. 